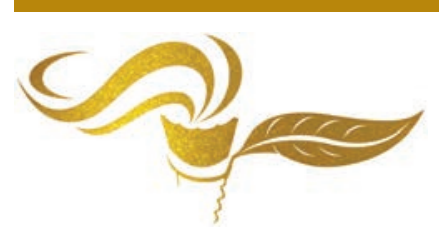

\title{
Is Transdisciplinary Education Engaging the 21st Century Engineering Student?
}

\section{Bob Stroud, Ph.D.}

Bob Stroud, Ph.D., Fellow, ATLAS, emial: bstroud628@verizon.net

Received 1 August, 2020; Revised 13 August, 2020; Accepted 14 August, 2020

Available online 14 August, 2020 at www.atlas-journal.org, doi: 10.22545/2020/00138

O bjective evidence shows whether contemporary engineering students are engaged by transdisciplinary education. This is done by first using a diffusion of innovations approach that isolates "transdisciplinary engineering" occurrences on the Internet from occurrences of disciplinary engineering, and then showing trends, forming conclusions, and making recommendations.

Keywords: Transdisciplinary engineering, transdisciplinary education.

\section{Introduction}

Basarab Nicholescu, in his paper Methodology of Transdisciplinarity - Levels of Reality, Logic of the Included Middle and Complexity [1], states:

"Transdisciplinarity is a relatively young approach; Swiss philosopher and psychologist Jean Piaget (1896-1980) developed the concept seven centuries after disciplinarity evolved. The word itself first appeared in France, in 1970, in the talks of Jean Piaget, Erich Jantsch, and Andr Lichnerowicz at the international workshop 'Interdisciplinarity - Teaching and Research Problems in Universities,' organized by the Organization for Economic Cooperation and Development (OECD) in collaboration with the French Ministry of National Education and University of Nice." [2]

By definition, transdisciplinarity relates across multiple domains concurrently as in Figure 1 from Ertas $[3,4]$. This paper shows whether contemporary engineering students, generally in disciplinary engineering domains, are being engaged by transdisciplinary education. The approach taken by the paper uses the degree to which occurrences on the Internet can be used as measure of diffusion and adoption [5, 6] of transdisciplinarity into engineering education. Since occurrences are discoverable by extant search engines (e.g., Google Scholar), a measure of transdisciplinary engagement is the frequency that "transdisciplinary engineering" occurs on the Internet over time. This is similar to the approach used by Roberts [5], Wognum et al. [7], Lee and Burr [8], Stroud [9], and Vanasupa and Thurman [10]. Because "transdisciplinary" integrates multiple domains, the search is carefully performed to isolate "transdisciplinary engineering" occurrences from disciplinary engineering occurrences. 


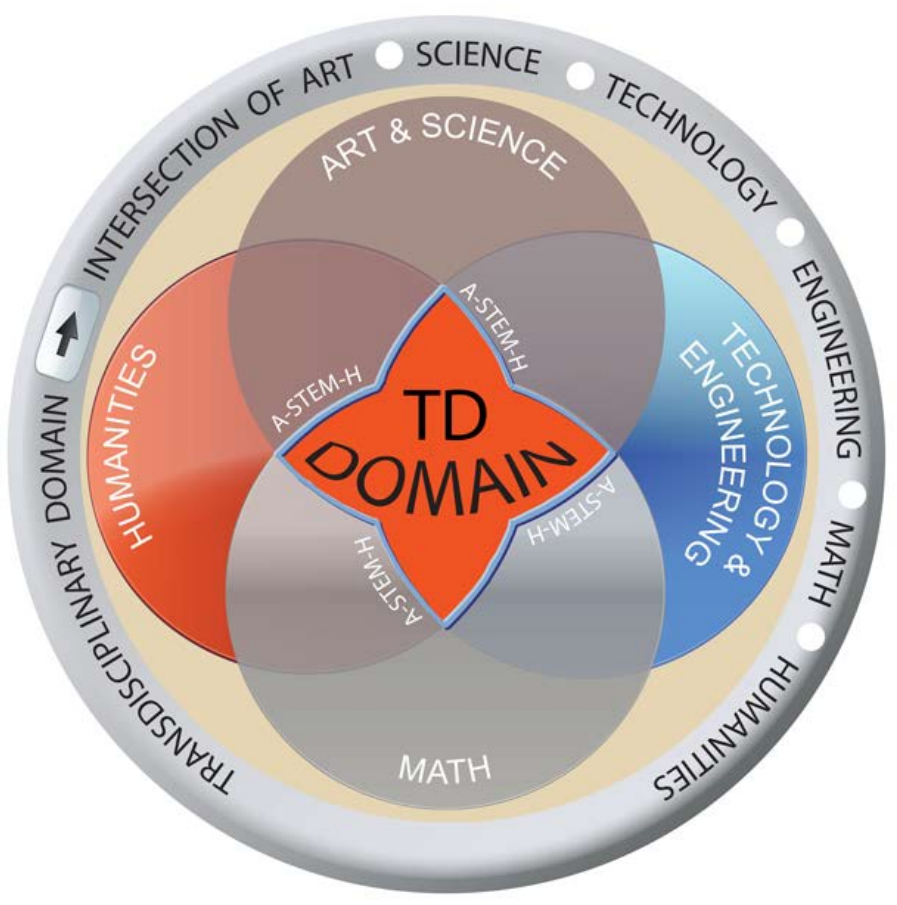

Figure 1: Ertas shows the transdisciplinary relationships among Arts, Science, Technology, Engineering, Math, and Humanities (A-STEM-H).

\section{Research Methodology}

This paper reports the results of time bounded occurrences of terms found on the Internet using Google Scholar. This is a numerical and not an inferential work like that of Adams [11]. It is merely indicative of the degree that transdisciplinary engineering is engaging contemporary engineering students via publications.

Recall that "transdisciplinarity" first appeared in 1970. The Internet occurrences (including patents and citations) returned by Google Scholar for "Transdisciplinary" and "Transdisciplinary Engineering" over five-year intervals beginning in 1970 are shown in Figure 2. Note the log scale in the ordinate.

These data show that cited occurrences increased for both "transdisciplinary" and "transdisciplinary engineering" with a dramatic increase in citations for "transdisciplinary engineering" in the last five-year interval.

Similarly, Figure 3 shows the occurrences for selected "disciplinary" engineering domains Electrical Engineering, Mechanical Engineering, Civil Engineering, Industrial Engineering, Petroleum Engineering, Nuclear Engineering, and Computer Engineering in the same intervals over the same period.

In the mainstream disciplines considered over the study period, all but "nuclear engineering" experienced a decline in the number of occurrences at or near the end of the study period, i.e., nearest the present time. This invites the question of whether this is somehow correlated with the "STEM" (Science, Technology, Engineering, Mathematics) concern that has the attention of the media, federal and state agencies, and legislative bodies in the United States [12-14] and elsewhere [15-17]. Or is it something else, such as an increase in emphasis on transdisciplinary engineering? Recall that "transdisciplinary" and "transdisciplinary engineering" occurrences, although far smaller in absolute terms, are not experiencing the same decline, though the increase in "transdisciplinary engineering.. publications does not account for the apparent decrease in disciplinary publications.

The data show that the occurrences of "transdisciplinary" on the web over time since 1970 have increased slightly more than a factor of almost 200. Occurrences of "transdisciplinary engineering" on the web over 
Bob Stroud

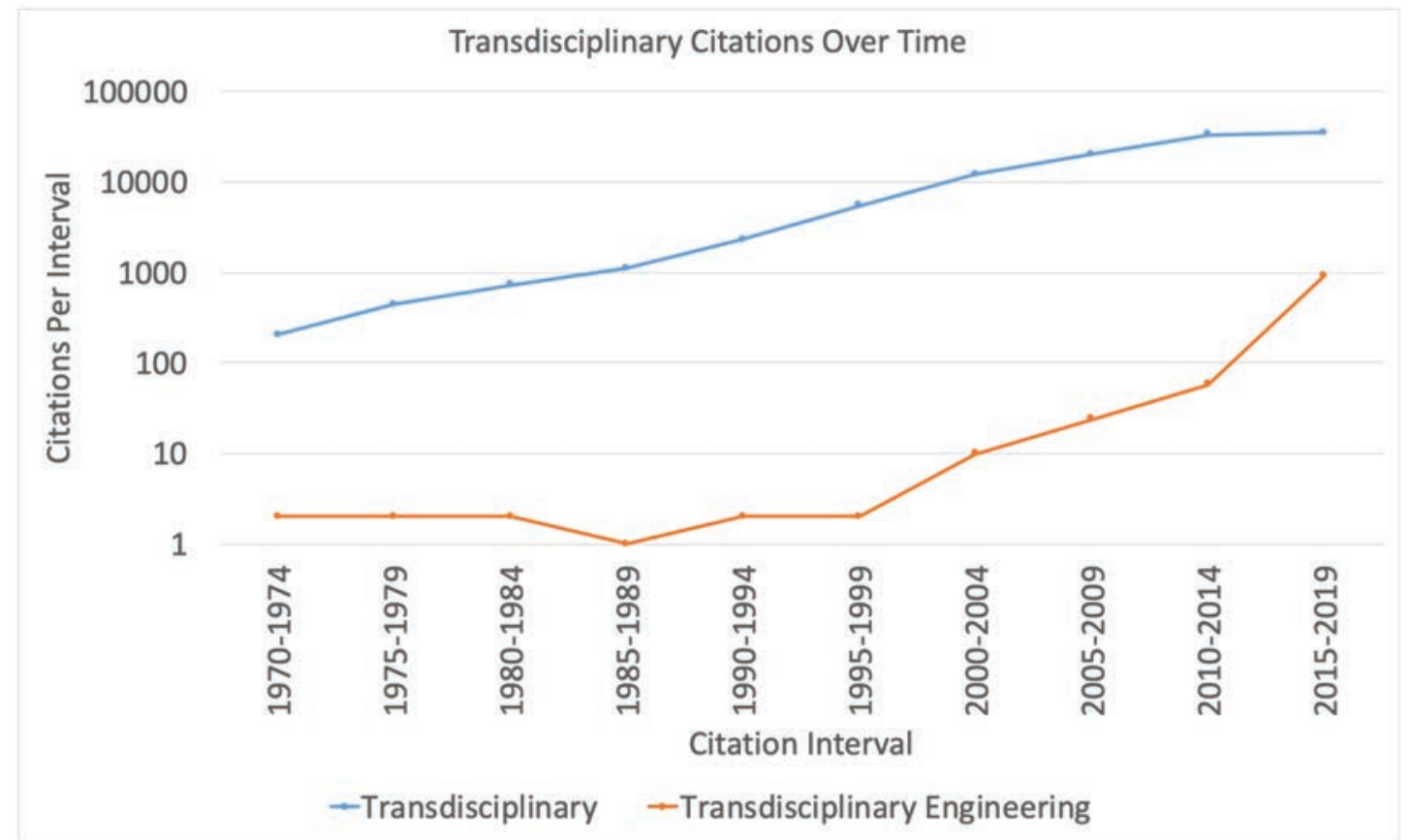

Figure 2: Internet occurrences for "Transdisciplinary" and "Transdisciplinary Engineering" over time since 1970 show increases over the period and that "Transdisciplinary Engineering" increased dramatically in the last five years.

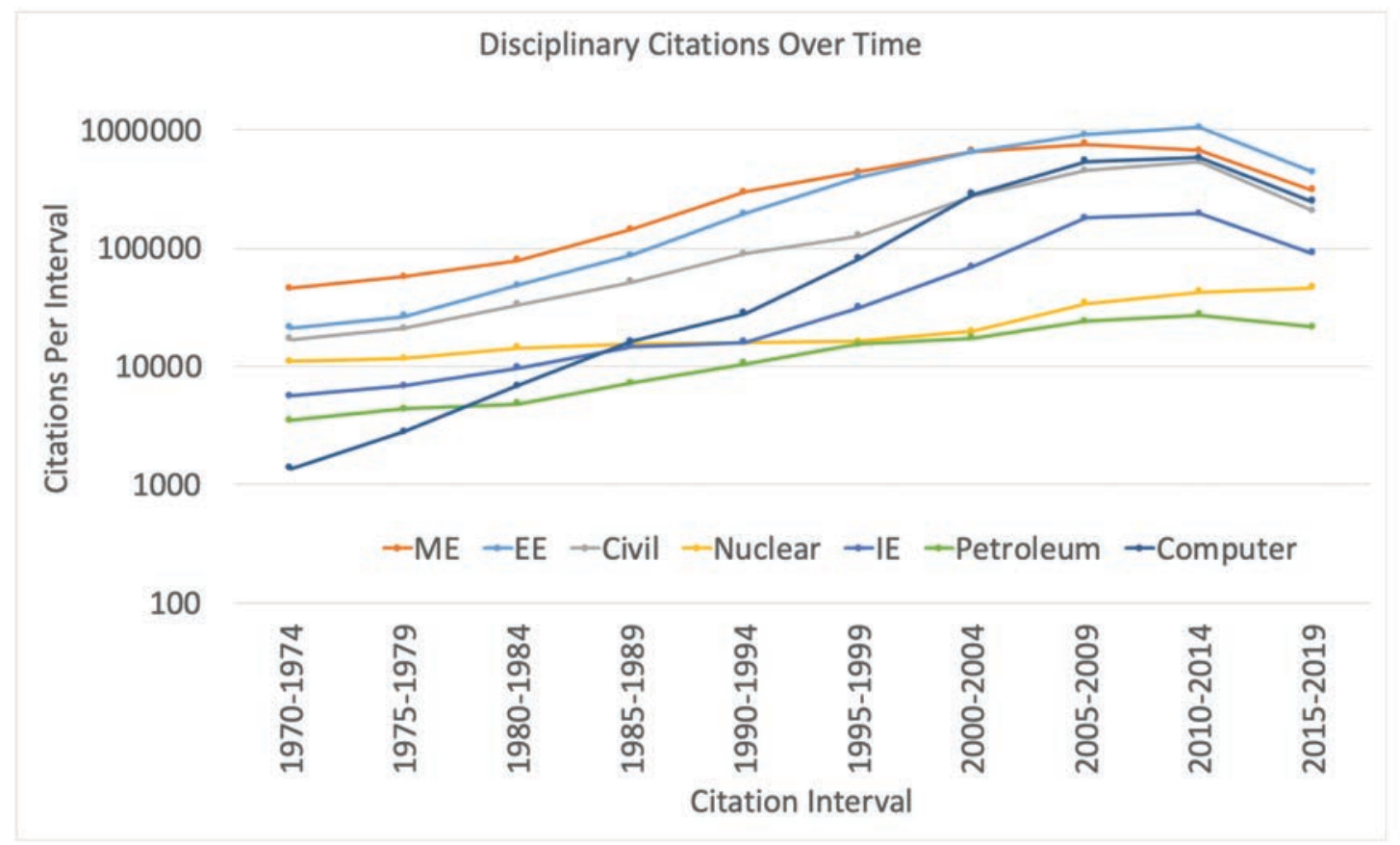

Figure 3: Internet occurrences for disciplinary engineering publications over time since 1970 show an increase over the period but a decrease in almost all of the last five years. 
time since 1970 have increased by a factor of almost 500. While occurrences of "transdisciplinary" were about 100 times more than occurrence of "transdisciplinary engineering" at the beginning of the study period (recall that "transdisciplinarity" was first used in 1970), by the end of the study period, the ratio was less than 40. One interpretation is that "transdisciplinary engineering" is further engaging those that publish their work, including students, in ways that are indexed and discoverable on the Internet. Further, disciplinary engineering occurrences increased over the survey period but almost all began to decrease from their peak near the present time. "Transdisciplinary" and "Transdisciplinary Engineering" occurrences increased over the survey period, and continue to increase.

\section{Discussion}

The trend suggested by the change in occurrences of "transdisciplinary" and "transdisciplinary engineering" over time is positive - "transdisciplinary engineering" occurrences are increasing faster than "transdisciplinary" occurrences and both are continuing to increase compared to most disciplinary occurrences on the Internet over the same time period.

The ATLAS web site home page at "Transdisciplinary Activities" shows a large list of "Transdisciplinary Research Programs" and journals (not all of these are specific to "Transdisciplinary Engineering"). ${ }^{1}$ One indication is that "Transdisciplinary Engineering" is becoming more "observable" (leveraging this term from control theory [18]) at least from a web index perspective. A simple way to foster this is to include terms such as "transdisciplinary engineering" in key words and abstracts of papers indexed by journals and discoverable by search engines. This is the "pull" side of publish/subscribe [19].

On the "push" side of publish/subscribe, disciplinary engineering students need to see concrete instances of how Transdisciplinary Engineering can inform and strengthen their practice. How does it directly lead to more responsibility, authority, compensation, employment [20], or something else about which they care? If not directly, then how does it help engineers solve contemporary problems such as better understanding and therefore management of complex systems? For example, in The Value of Transdisciplinary Collaboration in Robotics Education and Research [21], Santamaría shows how transdisciplinary engineering contributes to solving a contemporary problem in robotics through engineering and social science. In Systems Engineering in the Fourth Industrial Revolution [22], contributors Wognum, Mo, and Stjepandić offer applications of transdisciplinary engineering to an online hearing aid service system and a 3D printing licensing system. In Transdisciplinarity for Sustainability: A Unifying Framework for Navigating Transformational Learning Systems [10], Vanasupa and Thurman use a water capture and storage system as a model for an application of transdisciplinary engineering. In Information and the Future of Transdisciplinarity [23], Brenner notes that application of transdisciplinary principles to the engineering improves the common good by constructive contribution to the sustainable development of society through design and construction of devices that better reflect society's cognitive, social, emotional and informational needs.

A 2016 National Academies Workshop [24] noted "It may be that the traditional boundaries of disciplinary focus - reflected in the undergraduate 'major' and the graduate area of concentration are becoming increasingly blurred, resulting in a need for greater emphasis on interdisciplinary and transdisciplinary approaches to classroom instruction and labs. Institutions of higher education increasingly recognize the need to ensure that students have experiences in multiple disciplines and have the opportunity to work with faculty and other students across many different areas of focus and concentration. Because the workplace of the future may be characterized by an even greater 'convergence' of disciplines (and by the need for more STEM-capable workers even among those not in traditional STEM careers), the undergraduate and graduate level experiences for all students increasingly need to reflect this reality as well."

A 2017 National Academies report [25] denoted engineering research as "Multidisciplinary research primarily focused on technological innovation" and transdisciplinary engineering research as "... research

\footnotetext{
${ }^{1}$ At http://theatlas.org/index.php/td-research-programs, accessed 31 July 2020.
} 
focused on high-impact societal challenges, exploiting technological convergence and especially bringing in the social sciences as appropriate."

In his 2018 book Transdisciplinary Systems Engineering, Madni [26] states "Engineering education, which is at the heart of the engineering enterprise, has not kept pace with the needs of the twenty-first-century workforce" and "Unfortunately, engineering education today continues to focus on individual disciplines and narrow technical domains, ignoring the immense potential of cross-disciplinary education enabled by disciplinary convergence. This mindset will clearly need to change if progress is to be made in transforming engineering education."

In Philosophical Underpinnings of the Transdisciplinary Research Methodology [27] in 2018, McGregor states transdisciplinary researchers (to include transdisciplinary engineering researchers) "would identify any relevant theories (if they exist) to underpin the research, or develop new ones if required, decide on which literature and best practice to review pursuant to the complex problem, and develop a method for sampling, collecting and analyzing data and reporting the integrated, synthesized results". Emphasis added by the author. Reporting is understood to mean publishing.

A 2019 National Academies Workshop [28] reports "Peer-reviewed journal publication remains a primary currency of success. For convergent efforts that involve interdependent teams, a number of participants identified the need to understand and capture researcher contributions to overall success as part of full authorship lists, rather than simply as first or last author. As with funding proposals, journals may increasingly need to develop a peer review process and review criteria that can accommodate efforts combining multiple fields as part of cutting-edge research, including multiple areas of science, engineering, medicine, and social and behavioral sciences."

The same workshop further reported:"The same issues of allocating credit on collaborative publications and recognizing the impact of integrative publications outside the primary disciplinary journals used by a researcher apply to the evaluation process for promotion and tenure. Many participants suggested that researchers whose projects cross disciplines deserve a process for obtaining credit when doing so. One participant described the tenure process as a choke point in the academic environment. In general, numerous participants stated a need to be more explicit about what is involved in convergence and which criteria can be used to measure success. How scientists judge other scientists is critical to the culture of the community, and many participants voiced support for reshaping processes for intellectual credit, peer review, and advancement to support convergence. One question for debate is whether to create new kinds of tracks - for instance, team science, transdisciplinary, or convergence-focused tracks - or to change promotion and tenure criteria to encompass a greater variety of career trajectories. If pursued, significant further stakeholder engagement would be necessary to design a convergence tenure track."

In their 2019 paper To be or Not to be Transdisciplinary, That is the New Question. So, How to be Transdisciplinary? [29], Pasquier and Nicolescu observe that pedagogy needs to be "integrative" and "implicative": "Integrative means that every form of transmission is useful depending on the moments and the contexts. Implicative signals that pupils are offered situations to become fully actors of the process of their learning." Here, the contexts and the situation include publication of research results so that all can benefit from research.

In a 2020 National Academies Workshop [30], Shrivastava stated that academics have fragmented conversations in higher education into more than 8,000 different disciplines in the United States alone and more than 15,000 in the world, since scholarly disciplines are defined differently around the world. He suggested not trying to integrate across 8,000 disciplines, which is impossible, but to look at problems on the ground. "What is it that needs to be solved? [Then] bring in the relevant conversations in resolving those issues. That's what transdisciplinary science tends to do."

Thus, there is wide agreement that transdisciplinary education is an important augmentation of undergraduate and graduate education in general and engineering education in particular. 


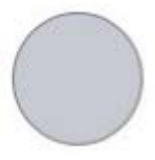

Disciplinary Application of one discipline or subject area only (such as biology, computer science, electrical engineering, graphic design, algebra).

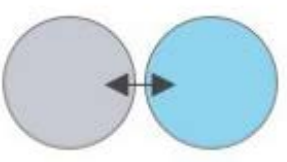

Multidisciplinary

Multiple disciplines work to solve a problem, with each discipline contributing a piece in additive fashion.

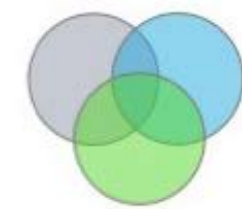

Interdisciplinary Multiple disciplines work together, with the result that the disciplines integrate their knowledge in a way that changes the original disciplines into something new.

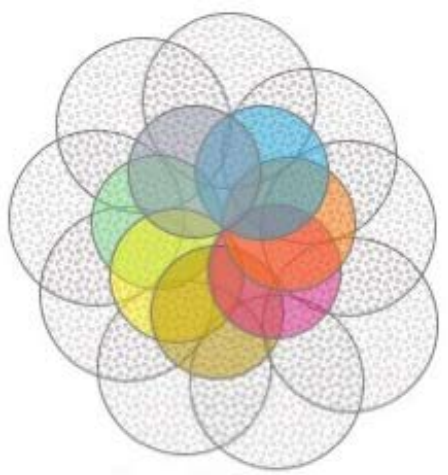

Transdisciplinary

Transdisciplinary work transcends traditional boundaries, involving knowledge and skills that benefit all disciplines, typically focused on addressing complex real-world issues.

Figure 4: Distinctions between disciplinary, multidisciplinary, interdisciplinary, and transdisciplinary applications ([31] as referenced in [25]; graphic adapted from Kelly and Burr [8]).

\section{Progress}

To measure adoption of transdisciplinary engineering education practices, the degrees offered and curricula at three major universities were examined for transdisciplinary engineering content and compared over time to assess the extent of transdisciplinary engineering education.

In 2013, a representative for Texas A\&M University (TAMU) in College Station, Texas stated "I am happy to indicate that we working on developing an undergraduate multidisciplinary engineering degree for the very near future. The goal is to allow students the flexibility of having breadth in multiple engineering disciplines to have concentrations in areas that require the breadth. We already have in place the graduate multidisciplinary engineering [Ph.D.] degree program, which is administered at the college level."

Elements of TAMU's engineering program are explicitly multidisciplinary or interdisciplinary but are not transdisciplinary in the sense shown in Figure 4 [8, 25, 31].

In 2013, "transdisciplinary" did appear in the course descriptions in the catalog, but in conjunction with departments or course offerings in English; Recreation, Park and Tourism Sciences; and Urban Planning, but not engineering. Third, except for two courses on generic directed studies and research, all the courses in the interdisciplinary engineering degree are drawn from traditional disciplinary programs.

In 2020, a similar examination of the course offerings at TAMU revealed just three courses whose descriptions includes the word "transdisciplinary". Two of these are graduate courses and one is an undergraduate course. None of these is an engineering course.

TAMU has made progress in integrating transdisciplinary education into its engineering program. For example, university engineering faculty and their students have been more active in conducting transdisciplinary engineering research: in 2019, the National Science Foundation (NSF) made an award for its 'Transdisciplinary Research in Principles of Data Science" (TRIPODS) initiative to TAMU. Thus far, no technical reports derived from this funding have been published that include the word "transdisciplinary," suggesting their publication regime could be more transdisciplinary forward in ways suggested in this paper.

\footnotetext{
${ }^{2}$ The author earned a BSEE degree from Texas A\&M.
} 
In 2014, a representative from Southern Methodist University (SMU) in Dallas, Texas ${ }^{3}$ had this comment regarding transdisciplinary engineering: "We don't have such a program. We do have a graduate design track in the ME department but not a Transdisciplinary design."

SMU offered a Ph.D. degree program in Systems Engineering that aimed to achieve the following educational goals:

- "Provide a solid foundation and depth in systems engineering theory and practice.

- Provide breadth across transdisciplinary engineering fields.

- Provide specialized contributions to the Systems Engineering Body of Knowledge through the Doctor of Philosophy dissertation."

Emphasis added by the author. An examination of the 2013 curricula at this university found the word "transdisciplinary" did not appear, and the course offerings do not appear to be transdisciplinary in the sense shown in Figure 4. For example:

"SYSTEMS INTEGRATION AND TEST. The process of successively synthesizing and validating larger and larger segments of a partitioned system within a controlled and instrumented framework is examined. System integration and test is the structured process of building a complete system from its individual elements and is the final step in the development of a fully functional system."

This was a reductionist approach [32] and not a transdisciplinary approach.

Five years later, the link to the Ph.D. program in Systems Engineering at SMU that could include transdisciplinary content is absent and the degree offerings no longer include the Systems Engineering Ph.D. program that had transdisciplinary content. This is representative of the continuing challenge facing diffusion of transdisciplinary engineering into engineering education.

Texas Tech University in Lubbock, Texas $^{4}$ in 2016 offered a transdisciplinary track in mechanical engineering that leads to a Ph.D. degree. The 2016 group was the fourth for this notionally four-year Ph.D. degree program that started over a decade earlier. The degree program for this track includes these three courses:

- Transdisciplinary Discovery and Innovation for Engineers

- Transdisciplinary Design Process \& Systems Complexity

- Transdisciplinary System Development Lifecycle and Management

This program clearly applies transdisciplinary engineering education.

In the United States in 2020, the Congressional Research Service (CRS) nor the Government Accountability Office (GAO) had relevant publications on transdisciplinary engineering. CRS had no reports that contain the word "transdisciplinary" while GAO had just 8 reports, none on transdisciplinary engineering. This is another avenue for diffusion of transdisciplinary engineering in the United States: further involve government.

Finally, this paper is an extension of work reported in 2016, and considers five additional years of corpora. Over the time elapsed since the prior work, there has been a dramatic increase in the peer reviewed published literature on "transdisciplinary engineering," indicative of further integration of transdisciplinary engineering into the undergraduate and graduate engineering program of study. But this increase in publication is not uniform across the university engineering education community, leaving further opportunities for advances.

\section{Conclusions}

In 1999, in his round table discussion paper The Transdisciplinary Evolution of Learning, Nicolescu said [33] "While not a new discipline or a new super-discipline, transdisciplinarity is nourished by disciplinary

\footnotetext{
${ }^{3}$ The author earned a MSEE degree at SMU

${ }^{4}$ The author earned a Ph.D. ME degree from Texas Tech
} 
research; in turn, disciplinary research is clarified by transdisciplinary knowledge in a new, fertile way. In this sense, disciplinary and transdisciplinary research are not antagonistic but complementary" and "The learning places should encourage and stimulate publications which record and analyze the major examples of innovative experience."

This paper accords with these premises. It shows the diffusion of transdisciplinary engineering into disciplinary engineering education can be measured by the number of publications that include key phrases such as "transdisciplinary engineering."

Transdisciplinary Engineering is still a small subset of the transdisciplinary publication domain but the rate of increase of "transdisciplinary engineering" occurrences on the Internet is faster than that of "transdisciplinary" occurrences on the Internet.

This trend indicates improving establishment of "transdisciplinary engineering" in general and of transdisciplinary engineering education in particular.

Disciplinary engineering occurrences seem to be decreasing at the present, and this may be an indicator of an underlying "STEM" problem that is not in the scope of this paper.

The endorsement of transdisciplinary engineering in secondary education may be improved by changing way promotion and tenure criteria emphasize transdisciplinary engineering.

Engineering educators should encourage the use of transdisciplinary engineering words in the publications of their research and the research of their students.

Funding: This research received no external funding.

Conflicts of Interest: The author declares no conflict of interest.

\section{References}

[1] B. Nicolescu, (2010). Methodology of Transdisciplinarity - Levels of Reality, Logic of the Included Middle and Complexity. Transdisciplinary Journal of Engineering 8 Science, vol. 1, no. 12, pp. 17-32.

[2] L. Apostel, G. Michaud, A. Briggs, and G. B. (ed.), (1972). L'interdisciplinarité : problémes d'enseignement et de recherche dans les universités. Paris: Centre Pour la Recherche et l'Innovation Dans l'Enseignement, Organisation de Coopération et de dévelopment economique, 1972.

[3] A. Ertas, (2014). Transdisciplinary Design Process $\&$ Sustainable Development. in iTextBook Transdisciplinary Learning Modules. United States: TheATLAS, 2014.

[4] A. Ertas, (2016). Transdisciplinary Trans-Sector Integration in Education: Convergence. Transdisciplinary Journal of Engineering $\&$ Science, vol. 7, pp. 55-68, doi: 0.22545/2016/00079.

[5] E. M. Rogers, (2003). Diffusion of Innovations. New York: The Free Press, p. 551.

[6] P. J. Denning and T. G. Lewis, (2020). Technology Adoption. Communications of the ACM, vol. 63, no. 6, pp. 27-29.

[7] N. Wognum, C. Bil, F. Elgh, M. Peruzzi, J. Stjepandić, and W. J. C. Verhagen, 2019). Transdisciplinary systems engineering: implications, challenges and research agenda. Int. J. Agile Systems and Management, vol. 12 , no. 1 , pp. 58-89.

[8] A. J. Stewart, M. P. Mueller, and D. J. Tippins, (2019). Eds. Converting STEM into STEAM Programs Methods and Examples from and for Education (Environmental Discourses in Science Education. Switzerland: Springer Nature.

[9] R. O. Stroud, (2016). Is Transdisciplinary Education Engaging the 21st Century Engineering Student?, presented at the TheATLAS Transdisciplinary-Transnational-Transcultural (T3) Conference on Design, Process \& Systems (DPS), Suzhou, China, 30 May.

[10] L. Vanasupa and C. J. Thurman, (2018). Transdisciplinarity for Sustainability: A Unifying Framework for Navigating Transformational Learning Systems. presented at the 2018 ASEE Annual Conference \& Exposition, Salt Lake City, UT, 2018, Paper ID \#22079.

[11] C. M. Adams, (2009). Developing Transdisciplinary Metrics Using Data Mining Techniques. Ph.D., Mechanical Engineering, Texas Tech, Lubbock, TX, 2009. 
Bob Stroud

Is Transdisciplinary Education Engaging the 21st Century Engineering Student?

[12] J. J. Kuenzi, (2008). Science, technology, engineering, and mathematics (STEM) education: Background, federal policy, and legislative action.

[13] A. P. Carnevale, N. Smith, and M. Melton, (2011). STEM: Science Technology Engineering Mathematics. Georgetown University Center on Education and the Workforce, 2011.

[14] X. Chen, (2009). Students Who Study Science, Technology, Engineering, and Mathematics (STEM) in Postsecondary Education. Stats in Brief. NCES 2009-161. National Center for Education Statistics, 2009.

[15] D. W. Hango, (2013). Gender differences in science, technology, engineering, mathematics and computer science (STEM) programs at university. Statistics Canada Ottawa.

[16] J. Williams, (2011). STEM education: Proceed with caution. Design and Technology Education: An International Journal, vol. 16, no. 1.

[17] Z. Lavicza, (2010). Integrating technology into mathematics teaching at the university level. ZDM, vol. 42, no. 1, pp. 105-119.

[18] J. Zabczyk, (2009). Mathematical control theory: an introduction. Springer Science \& Business Media.

[19] P. T. Eugster, P. A. Felber, R. Guerraoui, and A.-M. Kermarrec, (2003). The many faces of publish/subscribe. ACM Computing Surveys (CSUR), vol. 35, no. 2, pp. 114-131.

[20] C. Kreger, D. Moran, and S. Therson, (2017). A Transdisciplinary Approach to Unemployment In the United States' Petroleum Industry. Transdisciplinary Journal of Engineering ES Science, vol. 8, pp. 83-102, 2016, doi: $10.22545 / 2017 / 00089$.

[21] G. d. C. Santamaría, (2015). The Value of Transdisciplinary Collaboration in Robotics Education and Research. Transdisciplinary Journal of Engineering 6 Science, vol. 6, pp. 117-132, doi: 10.22545/2015/00062.

[22] R. S. Kenett, R. S. Swarz, and A. Zonnenshain, (2020). Eds. Systems Engineering in the Fourth Industrial Revolution. Hoboken, NJ: John Wiley \& Sons.

[23] J. E. Brenner, (2015). Information and the Future of Transdisciplinarity. Transdisciplinary Journal of Engineering \& Science, vol. 6, pp. 86-100, doi: 10.22545/2015/00065.

[24] National Academies of Science, Engineering, and Medicine, (2016). Developing a National STEM Workforce Strategy: A Workshop Summary.

[25] National Academies of Sciences, Engineering, and Medicine, (2017). A New Vision for Center-Based Engineering Research.

[26] A. M. Madni, (2018). Transdisciplinary Systems Engineering. Cham, Switzerland: Springer Nature.

[27] S. L. T. McGregor, (2018). Philosophical Underpinnings of the Transdisciplinary Research Methodology. Transdisciplinary Journal of Engineering ES Science, vol. 9, pp. 182-198, doi: 10.22545/2018/00109.

[28] National Academies of Sciences, Engineering, and Medicine, (2019). Fostering the Culture of Convergence in Research: Proceedings of a Workshop.

[29] F. Pasquier and B. Nicolescu, (2019). To be or Not to be Transdisciplinary, That is the New Question. So, How to be Transdisciplinary? Transdisciplinary Journal of Engineering \& Science, vol. 10, pp. 1-8, doi: $10.22545 / 2019 / 0110$.

[30] National Academies of Sciences, Engineering, and Medicine. (2020). Branches from the Same Tree: A National Convening on the Integration of the Arts, Humanities, and STEMM in Higher Education: Proceedings of a Workshop in Brief.

[31] K. L. Hall, A. L. Vogel, B. A. Stipelman, D. Stokols, G. Morgan, and S. Gehlert, (2012). A four-phase model of transdisciplinary team-based research: goals, team processes, and strategies. Translational Behavioral Medicine, vol. 2, no. 4, pp. 415-430.

[32] J. M. E. Gabbai, H. Yin, W. A. Wright, and N. M. Allinson, (2005). Self-Organization, Emergence and Multi-Agent Systems. in IEEE International Conference on Neural Networks and Brain, Beijing, China, 2005.

[33] B. Nicolescu, (1999). The Transdisciplinary Evolution of Learning. ed. Montréal, Canada: American Education Research Association. 


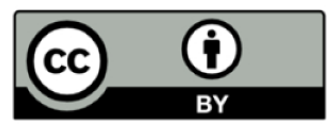

Copyright (C)2019 by the author. This is an open access article distributed under the Creative Commons Attribution License (https://creativecommons.org/licenses/by/4.0/), which permits unrestricted use, distribution, and reproduction in any medium, provided the original work is properly cited.

\section{About the Author}

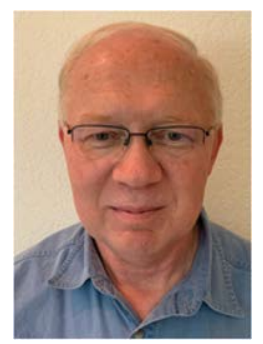

Dr. Robert O. "Bob" Stroud received a BSEE from Texas A\&M University, College Station, Texas, USA, a MSEE from Southern Methodist University, Dallas, Texas, USA, and a Ph.D. in ME from Texas Tech University, Lubbock, Texas, USA. He worked for the Raytheon Company (now Raytheon Technologies) from 1978 until he retired as a Senior Engineering Fellow in 2019. As part of his duties, he taught courses in Principles of Systems Engineering (PoSE), the Department of Defense Architecture Framework (DoDAF), and the Systems Engineering Technical Development Program (SEtdp). While at Raytheon, he completed the Ph.D. Transdisciplinary Design - Process \& Systems Track in the mechanical engineering department at Texas Tech. His dissertation was on Complexity Frameworks in Enterprise Design. His research interests include engineering complexity and transdisciplinary engineering. He belongs to the Institute of Electrical and Electronics Engineers (IEEE) and the Association for Computing Machinery (ACM) professional societies. In 2016, The Academy of Transdisciplinary Learning and Advanced Studies (TheATLAS) elected him to the grade of Fellow. 